\title{
Astronomía y arquitectura en el norte de la península de Yucatán: Análisis comparativo entre Chichén Itzá y Dzibilchaltún
}

Orlando J. Casares Contreras

\section{Resumen}

El urbanismo de la sociedad maya es un reflejo adaptativo y del aprovechamiento de los recursos naturales a su alcance para satisfacer sus necesidades, pero también pudo representar a través de los arreglos arquitectónicos al interior del asentamiento, una conmemoración simbólica de su cosmovisión en las que la propia naturaleza representó un elemento sagrado al cual se le vinculó con estructuras en las que, los eventos astronómicos que contienen son pieza clave del arreglo arquitectónico, urbanístico y religioso. En Dzibilchaltún y Chichén Itzá, los conceptos del inframundo, los elementos acuáticos y la astronomía son piezas fundamentales que se ven representadas en un período de traslape temporal a través de su arquitectura, vinculado con las ceremonias agrícolas y la fertilidad.

Palabras clave: Arqueoastronomía, Agricultura, Chichén Itzá, Dzibilchaltún, Urbanismo

\section{Abstract}

Urbanism of Maya society is an adaptive use of natural resources to their needs, but also, represent through architectural arrangements within the settlement, a symbolic commemoration of their worldview in which the nature represented is a sacred element to which it is linked to structures in which, containing astronomical events are key piece of architectural, urban and religious settlement. In Dzibilchaltún and Chichén Itzá, concepts like the underworld, water elements and astronomy are fundamental pieces that are represented in a temporary period of overlap through its architecture, linked with agricultural ceremonies and fertility 
Keywords: Archaeoastronomy, Agriculture, Chichen Itza, Dzibilchaltun, Urbanism

Orlando J. Casares Contreras, Centro INAH Yucatán. INAH (Instituto Nacional de Antropología e Historia), Sección Museografía, Oficina Centro INAH Yucatán, en Mérida, Yucatán, México. 


\section{INTRODUCCIÓN}

Los estudios sobre urbanismo en Mesoamérica han tenido diferentes momentos y tendencias que nos muestran la complejidad del tejido social y las dinámicas de sus habitantes, así como el conocimiento que tuvieron sobre el aprovechamiento de los recursos naturales a su alcance a partir del establecimiento de sus ciudades. Este argumento ha sido empleado en los trabajos sobre el patrón de asentamiento de sitios arqueológicos, especialmente en aquellos pertenecientes al área maya.

En dichas investigaciones sobre el patrón de asentamiento de sitios mayas, el aspecto astronómico no ha sido suficientemente abordado, salvo algunas investigaciones en torno a las alineaciones entre estructuras de conjuntos arquitectónicos, como aquellas entre las distancias de una estela con respecto a otra de más de un kilómetro o entre alineaciones en posiciones extremas con astros visibles como Venus hacia asentamientos prehispánicos cercanos sin que ello represente hasta el momento, algún patrón común a una época, región o se le vincule con otros aspectos propios de la cosmovisión maya.

$Y$ es que, aquellos modelos que inicialmente planteaban que las construcciones de los mayas estaban alineadas a los cuatro puntos cardinales no tuvieron mayor sustento y con el avance de la arqueología en el área maya, se ha visto que la distribución urbanística entre los espacios ceremoniales, civiles y habitacionales es mucho más compleja, no siempre respondiendo a éste principio, incluso en la propia alineación de una estructura vista de forma aislada, tampoco se ha visto un patrón que responda al mismo argumento.

Pero ello no quiere decir que dentro de los principios de la distribución arquitectónica de algunos sitios, no existiera una relación entre los elementos de la cosmovisión maya con alineaciones astronómicas y como muestra de ello, en el presente documento se expondrá una comparativa de dos asentamientos, que aunque temporalmente presentan sus diferencias, en algún momento se traslapan y justamente en ese espacio también parecen compartir un patrón urbanístico similar, en donde el conocimiento astronómico presente en las mismas junto con sus principios religiosos presentan concordancias apoyadas en los elementos naturales que ambas ciudades contienen.

Estamos hablando de los asentamientos prehispánicos de Dzibilchaltún y Chichén Itzá, específicamente de los arreglos arquitectónicos del conjunto de las Siete Muñecas con el resto del sitio y con la Gran Nivelación de Chichén Itzá, la cual se repite en el conjunto del Osario. Estas tres composiciones urbanísticas tienen 
similitudes ya que constan de una estructura piramidal con cuerpos escalonados en sus cuatro lados, que a su vez contienen una subestructura y en dichos casos, la estructura y/o la subestructura posee una alineación o arreglo con el cuál es posible registrar eventos astronómicos relacionados con el calendario y pasos del Sol por el Cenit.

De igual manera, éste arreglo espacial de la estructura está ligada con el resto del asentamiento a través de una calzada que lo conecta con la fuente de agua más importante del propio asentamiento, como lo son los cenotes. En las siguientes páginas, exploraremos con mayor detenimiento los detalles arquitectónicos y arqueoastronómicos de cada sitio y de sus estructuras involucradas para un posterior análisis de cómo es que en una época que va del Clásico Tardío al Terminal, podría representar parte de algún culto que involucró eventos astronómicos relacionados con la agricultura y la llegada de las lluvias, con el inframundo y sus elementos acuáticos.

\section{LA ESTRUCTURA 1-SUB O LAS SIETE MUÑECAS DE DZIBILCHALTÚN.}

La Subestructura 1 de Dzibilchaltún o también denominada como "El Templo de las Siete Muñecas" pertenece al sitio arqueológico del mismo nombre, ubicado al norte de Mérida, la capital del estado mexicano de Yucatán. Su ubicación geográfica en coordenadas es $21^{\circ} 05^{\prime}$ latitud norte y $89^{\circ} 35^{\prime}$ longitud oeste (las cuales fueron determinadas por GPS desde la escalinata poniente de la subestructura y rectificadas por la aplicación Google earth). El sitio tiene diferentes períodos ocupacionales pero para fines del presente artículo, nos enfocaremos a las características de la estructura anteriormente mencionada.

Se ubica en un grupo de estructuras llamado el "Grupo de las Siete Muñecas" (Figura 1) e inicialmente fue excavado por un equipo de arqueólogos norteamericanos, encabezados por Wyllys Andrews IV a mediados del siglo pasado (1980: 4 y 5). Este grupo arquitectónico data de inicios del período temprano II, equivalente al clásico tardío (600 al 800 d.C.) hasta su última fase de ocupación que fue en el floreciente puro, que coincide con el clásico terminal (800 al 950/1000 d.C.), según se pudo fechar por cerámica y algunas muestras de carbono 14 en la estructura (Andrews IV 1980: 273). 


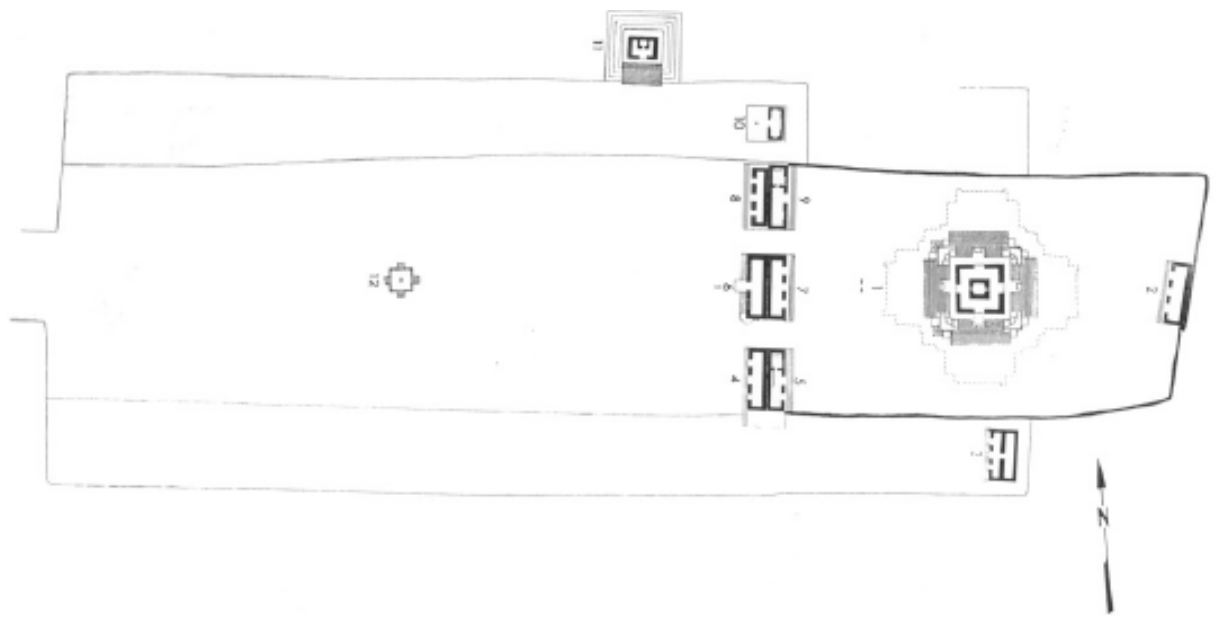

Figura 1. Grupo de las Siete Mueñacas (Tomado Andrews IV: 1980: 83).

En cuanto a la estructura principal, los arqueólogos encontraron restos de una etapa constructiva posterior, la cual fue denominada como la Estructura 1, pero por su estado de conservación, el equipo de arqueólogos norteamericanos decidió retirar la mayor parte para restaurar la subestructura, la cual por las mismas razones denominaron subestructura 1 y es visible hoy en día, la cual data del período clásico tardío (Andrews 1980: 85). La misma se encuentra representada en la figura 1 con el contorno delinieado y es presentado para su comparación de una reconstrucción hipotética hecha por Andrews IV en la figura 2.

Arquitectónicamente, consta de elementos como el Talud Tablero con nicho remetido, que se ha sugerido como un marcador de influencia teotihuacano para Mesoamérica pero también con elementos propios de las tierras mayas, especialmente en sitios con desarrollos del clásico temprano (o anteriores) como Uaxactún, Kohunlich, Piedras Negras, Tikal, Lamanai o Cerros, los cuales tienen la regularidad de encontrarse con mascarones de estuco como parte de la decoración de los mismos (Andrews 1987: 20 y Maldonado 2003: 487). 

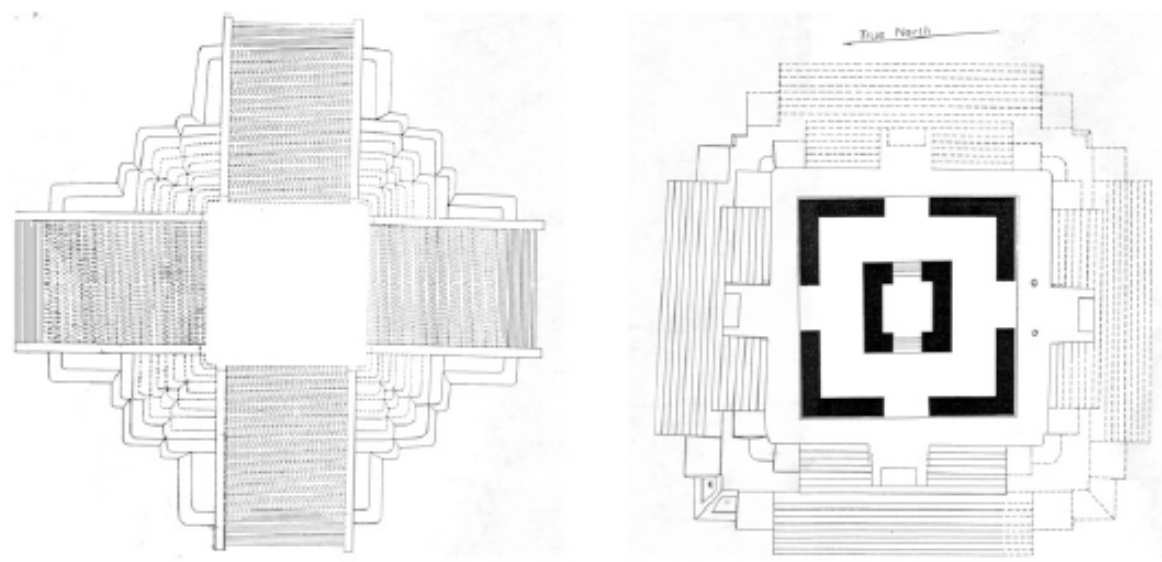

Figura 2. Dibujos de las plantas de la Estructura 1 (izquierda) hoy desaparecida y su Subestructura (derecha), la cual está restaurada (Andrews IV 1980).

De los trabajos derivados de las temporadas arqueológicas de la Tulane, la subestructura 1 ha mostrado un particular interés, no sólo por los arreglos arquitectónicos sino por las ofrendas, grafitis e inscripciones en su interior. Una de ellas y quizá la más destacada, son unas siete figurillas halladas en la cámara interior del templo (Figura 3) las cuales fueron burdamente elaboradas de barro, pero resaltan sus atributos fálicos y sexuales por encima de las proporciones de la pieza (Andrews IV 1980: 113), razón por la cual lleva el nombre de Templo de las Siete Muñecas. 


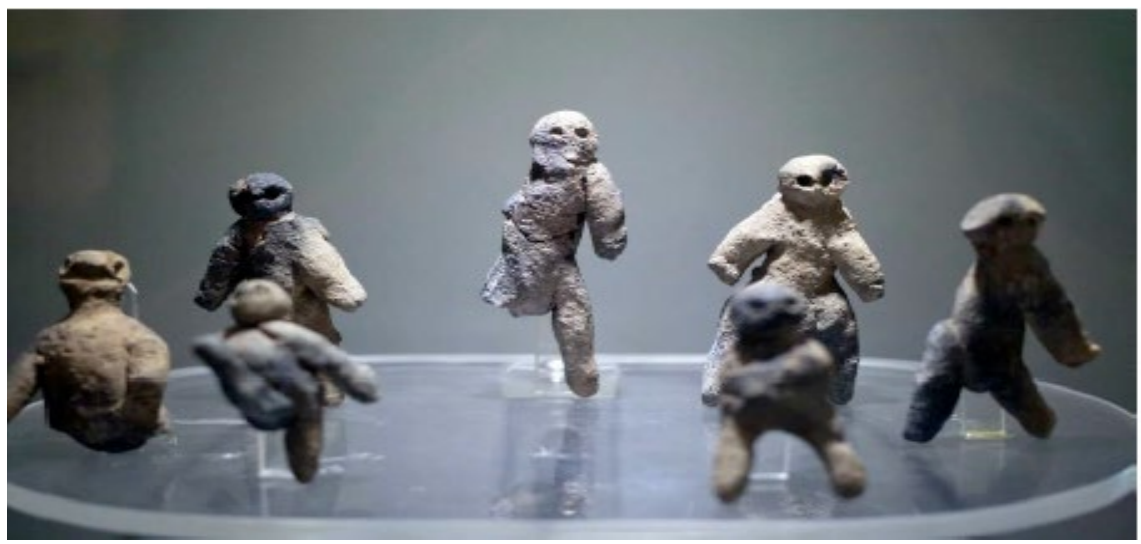

Figura 3. Ofrendas halladas en la cámara interior de la Subestructura 1 de Dzibilchaltún (fotografía propia). Actualmente se encuentran en el museo de sitio del lugar.

Otro de los elementos simbólicos más destacados, son las representaciones registradas en los estucos de las fachas al momento de la liberación de la subestructura, donde originalmente se había propuesto que ello respondía a una influencia de las culturas del Golfo de México, ya que entre los elementos iconográficos que se registraron según los investigadores norteamericanos, habían peces, mantarrayas y una probable ave acuática (Andrews IV 1980 y Andrews V 1978). Dichos elementos serán revalorados en el análisis del presente artículo.

En términos astronómicos, los trabajos arqueoastronómicos de Víctor Segovia (Casares 2001: 5), demostraron que es posible hacer una observación desde fachada oriente de la Estructura 7, en la que se registra el paso del Sol durante los equinoccios ${ }^{1}$ como el referido en la Figura 4 . En trabajos posteriores realizados por Clemency Coggins (1988) y Jesús Galindo (1994), las observaciones hacia lo que se denominó equinoccio astronómico no coincidieron con los primeros planteamientos hechos por Segovia, ya que dicha observación tenía su plenitud de 3 a 4 días antes o después de los equinoccios astronómicos. Posteriormente, Casares rectificó las mediciones, dando un promedio de 2 a 3 días antes y después del equinoccio astronómico (Casares 2001: 10).

\footnotetext{
${ }^{1}$ Aunque el término de observación equinoccial se ha puesto en debate por Ivan Sprajc, se menciona en éste apartado tal cual fue propuesto por Víctor Segovia, es decir, como observación de los equinoccios de primavera y otoño.
} 


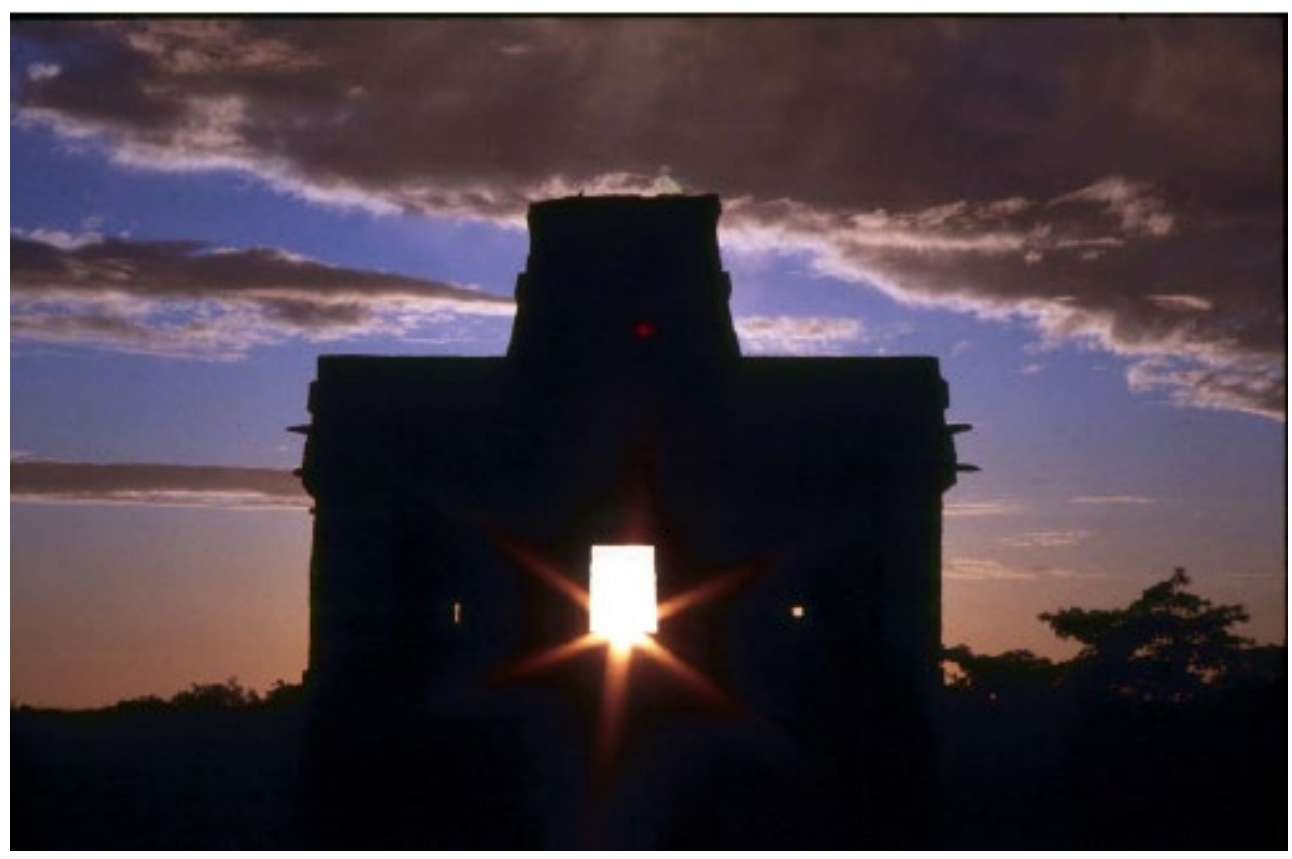

Figura 4. El Sol saliendo por la Subestructura 1 el 19 de marzo de 2001 (fotografía de Orlando Casares).

En dicha intervención, también se propuso que las funciones astronómicas de la Subestructura 1 podían ir más allá de la observación denominada equinoccial y de las solsticiales propuestas inicialmente por Víctor Segovia, sino que debido a los criterios de restauración y que no se respetaron in situ muchos de los elementos arquitectónicos intervenidos por los arqueólogos norteamericanos, es que la llamada Chimenea que retama la parte superior de la subestructura, la cual pudo funcionar como un observatorio cenital para los días 25 de mayo y 17 de junio (Casares 2001: 16). Lamentablemente, sólo puede comprobarse teóricamente, porque dicho elementos ajeno forma parte de la restauración actual. 
En el contexto urbano del grupo arquitectónico de las Siete Muñecas, cabe agregar que éste se conecta con el resto del sitio a través de una calzada que lleva a la plaza central del sitio, que no sólo se encuentra rodeada de estructuras de tipo administrativas sino que a su costado suroeste se ubica un cenote abierto, cuya importancia natural y ritual se ha hecho patente a través de las ofrendas encontradas en su interior (Andrews IV 1980).

\section{EL CASTILLO DE CHICHÉN ITZÁ Y SUS ALREDEDORES.}

El sitio arqueológico de Chichén Itzá, se ubica al centro del Estado de Yucatán y las coordenadas del sitio corresponden a $20^{\circ} 40^{\prime}$ latitud norte y $88^{\circ} 34^{\prime}$ longitud oeste (al igual que en Dzibilchaltún, fueron hechas por GPS desde la escalinata norte de la estructura "El Castillo" y rectificadas por la aplicación Google earth). Éste ha sido una de las zonas más estudiadas y cuyo interés académico ha generado una constante variedad en interpretaciones sobre cada una de sus estructuras, sus significados y simbolismos.

El sitio presenta diferentes períodos ocupacionales, tradicionalmente se había considerado que iniciaron con el Clásico Terminal (900 al 1,000 d.C.) y alcanzan su mayor apogeo durante el Posclásico Temprano (1,000 al 1,200 d.C.) donde se consolida como una de las grandes capitales regionales, pero se ha propuesto que éste asentamiento tuvo un colapso a finales del último período mencionado según las investigaciones arqueológicas entre 1930 a 1960 y la consulta de fuentes etnohistóricas (Cobos 1997: , Gallareta 1989: 330 y Schmidt 1994: 24 y 25).

Otra de las propuestas más recientes, apoyadas en la epigrafía y nuevos hallazgos arqueológicos, han sostenido que éste momento de apogeo comenzó desde finales del Clásico Tardío (700 - 800 d.C.) y durante el Clásico Terminal (800 - 1000 d.C.) en dicha región, por lo que su colapso ha sido retrasado hacia principios del Posclásico Terminal (1050 d.C.) y no a finales de éste. También dicha propuesta, argumenta que Chichén Itzá ya funcionaba como capital regional e interactuaba con distintos sitios contemporáneos del norte de la Península de Yucatán, así como de sus relaciones con otros sitios lejanos, que van desde la Costa del Golfo de México hasta Centroamérica (Cobos 1998: 915). Para los fines de nuestra propuesta, éste es la versión en temporalidad que adoptaremos para Chichén Itzá.

En nuestro caso, nos enfocaremos a un conjunto urbanístico conocido como La Gran Nivelación, en la que se encuentra la Estructura 2D5 conocida como El Castillo, también llamada Templo de Kukulkan, la cual ha sido usada como uno de los principales íconos arqueológicos y turísticos del mundo maya. La estructura 
cuenta con una subestructura que por ser anterior, se había fechado para el Clásico Terminal (Kubler 1961:47), pero ante la nueva evidencia, es posible que su construcción se ubicara a finales del Clásico Tardío y la estructura que hoy vemos, al ser posterior se ubique en el Clásico Terminal. En plano del núcleo principal del asentamiento (Figura 5) se puede apreciar las estructuras de la Gran Nivelación y de ellas, una réplica de la misma disposición en el Grupo del Osario.

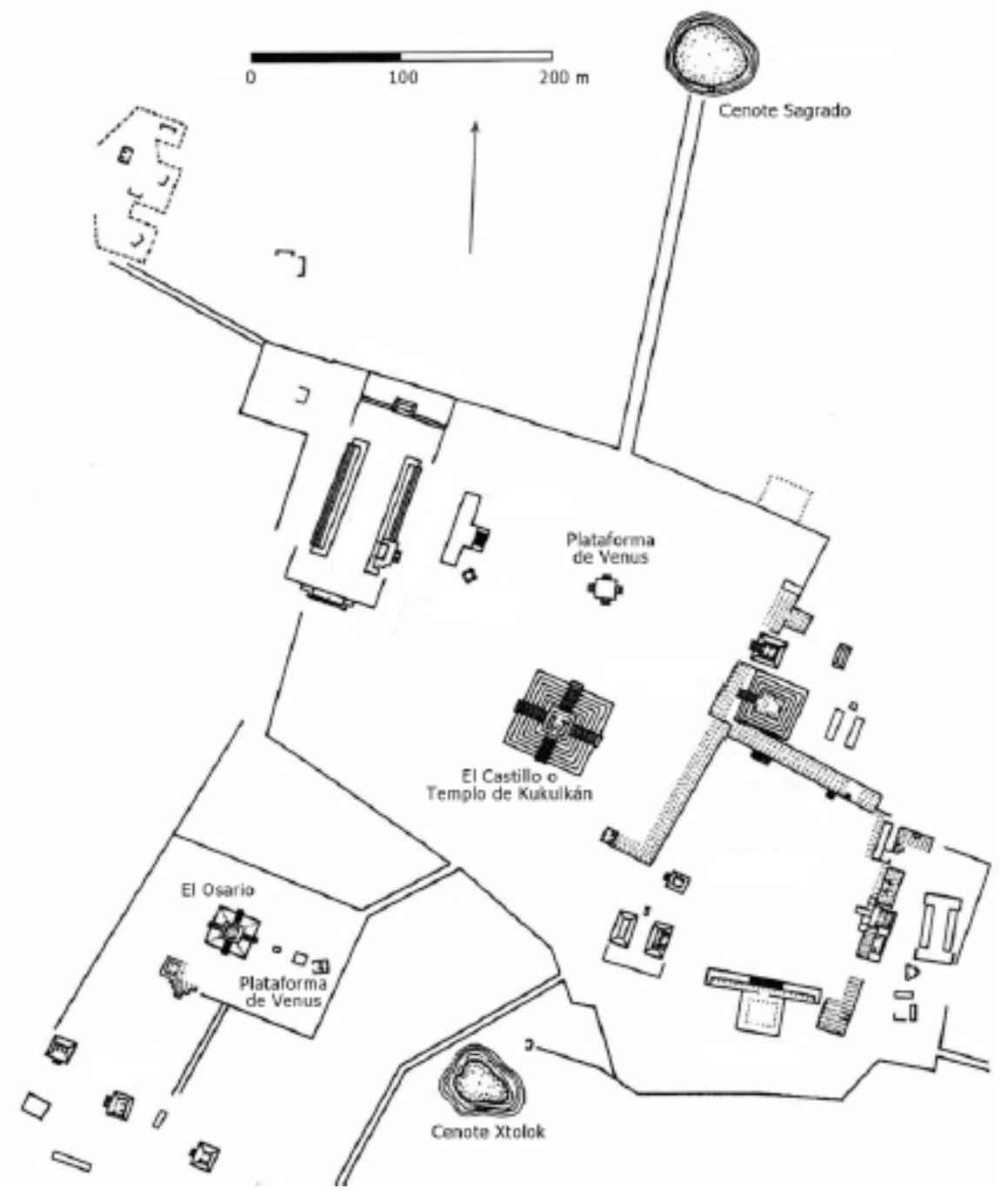

Figura 5. Mapa de la zona central de Chichén Itzá. 
La subestructura del Castillo cuenta con una sola escalinata de acceso al templo superior, ubicada hacia el norte y correspondiente con la escalinata norte de la estructura que la contiene por encima así como elementos zoomorfos que la decoran en su templo superior. En ambas estructuras de tipo piramidal se pueden apreciar en los basamentos que las conforman, elementos del llamado Talud Tablero en cada uno de sus costados. La estructura principal, está conformada por cuatro escalinatas y un templo en su parte superior, en la misma, se destaca el lado norte por encima del resto, ya que contiene elementos zoomorfos (serpientes) que descienden al nivel más bajo y señalan hacia la calzada norte que lleva al principal cenote del asentamiento, como lo refiere el comparativo de la Figura 6.

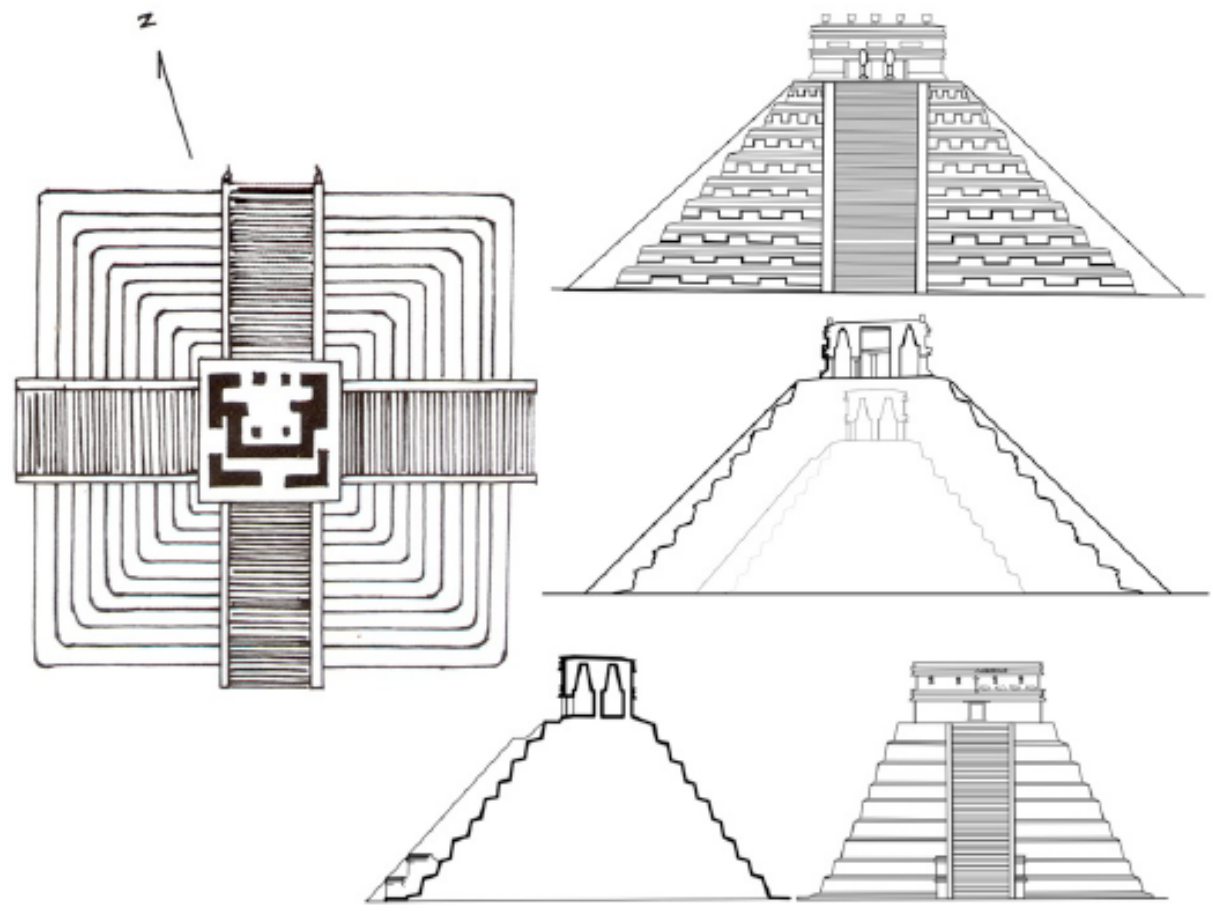

Figura 6. Elevaciones, cortes y planta de la estructura "El Castillo" así como de su subestructura. 
A un costado, justamente en la misma dirección de la escalinata norte de El Castillo, antes de llegar a la calzada que dirige hacia el Cenote Sagrado se localiza un basamento de pequeñas dimensiones, con escalinatas en cada uno de sus lados la cual es llamada La Plataforma de Venus. En ella, se destacan elementos de serpientes emplumadas y representaciones repetidas del glifo de estrella (Figura 8), por lo cual, adquirió el nombre y la asociación con el planeta Venus. Ésta misma disposición urbanística arquitectónica ubicada entre los edificios de la Gran Nivelación se repite en el Grupo del Osario, conformado por una pirámide con basamentos en talud tablero, cuatro escalinatas en sus costados y un templo en la parte superior pero que señala al oriente junto con las cabezas de serpientes en los costados de su escalinata, señalando la calzada 15 que da al Cenote Xtolok (Fernández 1999: 264).

En términos astronómicos, la Estructura 2D5 o El Castillo ha sido una de las más estudiadas y quizá sea el evento arqueoastronómico más destacado de Mesoamérica, siendo éste una hierofanía en la que en fechas cercanas ${ }^{2}$ al equinoccio de primavera y otoño, por lo que se aprecia un juego de sombras en las que se forman triángulos de luz que van señalando la cabeza de una serpiente emplumada encontrada en la alfarda norte de la estructura (Figura 7). Este evento astronómico también atrae a turistas de todas las nacionalidades, especialmente durante el 21 de marzo, además de que en México es una fecha festiva importante.

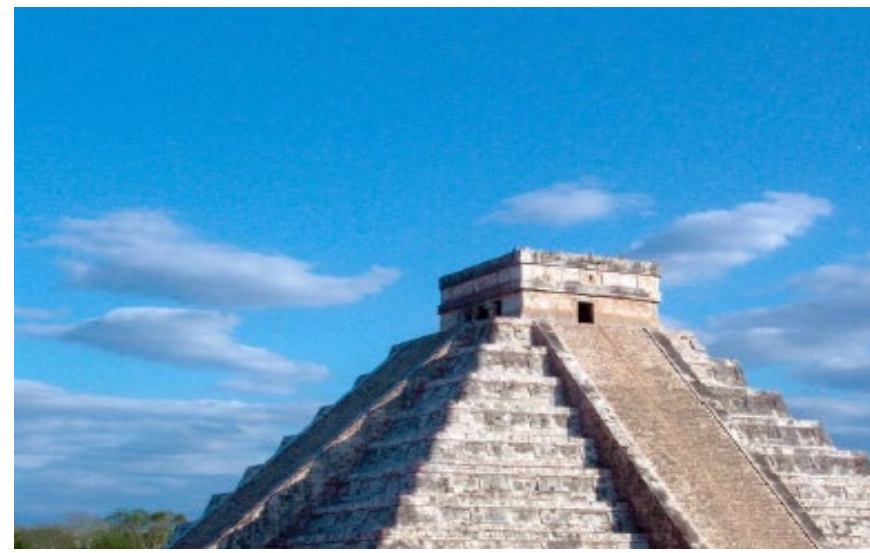

Figura 7. Hierfanía formada por triángulos de luz el día 20 de septiembre de 2005 (fotografía de Orlando Casares).

\footnotetext{
${ }^{2}$ Existe una controversia en torno a si las fechas señalan con precisión el equinoccio astronómico o si son una aproximación al mismo. Por el momento omitiremos dicha discusión en éste apartado, para retomarla y proponer algunas consideraciones en los apartados finales del presente documento.
} 
Otro de los aspectos en los que se han enfocado muchas de las investigaciones arqueoastronómicas son en sus simbolismos solares y calendáricos. Uno de los primeros trabajos al respecto fue presentado por Luis Arochi en 1974 y publicados en un libro en 1984 (el mismo reconociendo que anteriormente este evento ya había sido reportado por trabajadores del sitio) en el cual no sólo lo describe y hace una comparación con estructuras similares dentro del mismo sitio (El Osario) sino con otras de sitios mayas cercanos (El Castillo de Mayapán) sino que también lo relaciona con el calendario maya, especialmente el Haab de 365 días a través de aspectos de su geometría como el número de escalones, basamentos, etc. (Arochi 1998: 61-74). Posteriormente se hablaron de distintas versiones interpretativas al mismo evento pero sin mayores cambios a los anteriormente descritos.

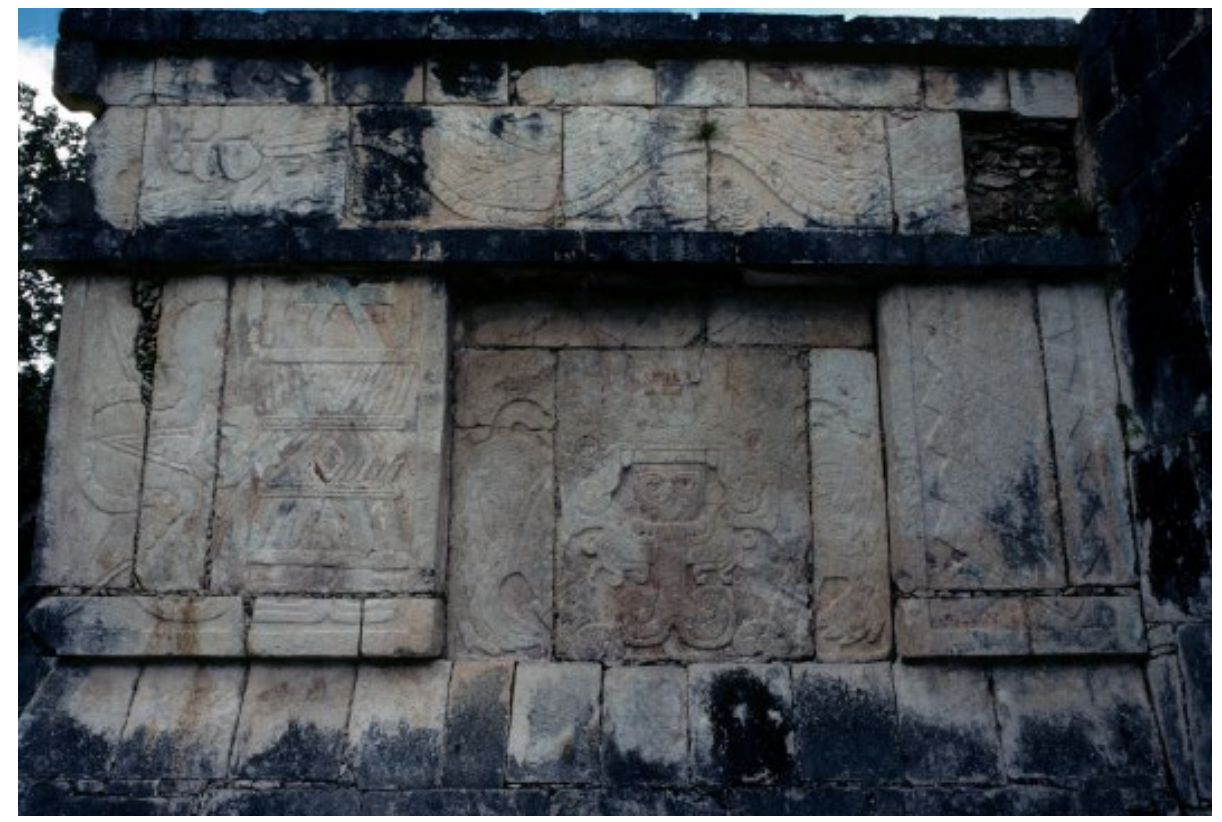

Figura 8. Detalles de la iconografía Plataforma de Venus, la oriente, en la Gran Nivelación (Fotografía de Orlando Casares).

Uno de los trabajos que han dado nuevas revelaciones en materia astronómica hacia ésta estructura, con elementos novedosos ha sido el realizado por Arturo Montero y Guillermo de Anda en 2011, en la cual propone la observación de los pasos del Sol por cenit del lugar como parte de la orientación que tiene la estructura, especialmente durante el ocaso en los días que ocurre ese evento (23 de mayo y 19 de julio), especialmente en dirección hacia el Cenote de Holtún a unos $291^{\circ}$ 
azimut en un horizonte plano. Posteriormente, este dato fue corroborado por los investigadores Jesús Galindo y David Wood (Montero 2013: 149 y 2014: 81-83).

Este mismo patrón urbanístico - astronómico se repite en el mismo sitio pero con una menor escala, al sur de la gran nivelación y es conocido como el Grupo del Osario. En éste, se ubica una estructura piramidal escalonada (Estructura 3C1) conocida como El Osario o La Tumba del Gran Sacerdote(Figura 9) con direcciones similares a El Castillo, una plataforma circular al oriente y una plataforma igualmente llamada Plataforma de Venus, las cuales conectan con una calzada (Sacbé 15) que dirige al cenote Xtolok (Fernández 1999: 265). Astronómicamente es posible vislumbrar un descenso en las alfardas decoradas con motivos crotálicos y rematan en su parte inferior con una cabeza de serpiente con efectos de luz y sombra, pero en fechas ligeramente distintas a las de El Castillo, siendo visible el 18 de marzo y 25 de septiembre.

En su interior hay una cavidad en forma de caverna cuyo interior con fue encontrado con siete tumbas con restos humanos (Thompson 1938: 43). Ésta misma entrada, pudo también ser usada para la proyección del Sol durante los pasos del mismo por el meridiano del lugar. Entre los relieves, se pueden observar figuras humanas en los pilares del templo superior con atavíos de influencia del centro mexicano (llamados Pahuatues por el Peter Schimidt) y en sus relieves, elementos zoomorfos de pájaros divinos, con posturas de enfrentamientos y ofrendas de frutas, semillas y orntamentos a los lados (Schmidt 2011: 1169 - 1171).

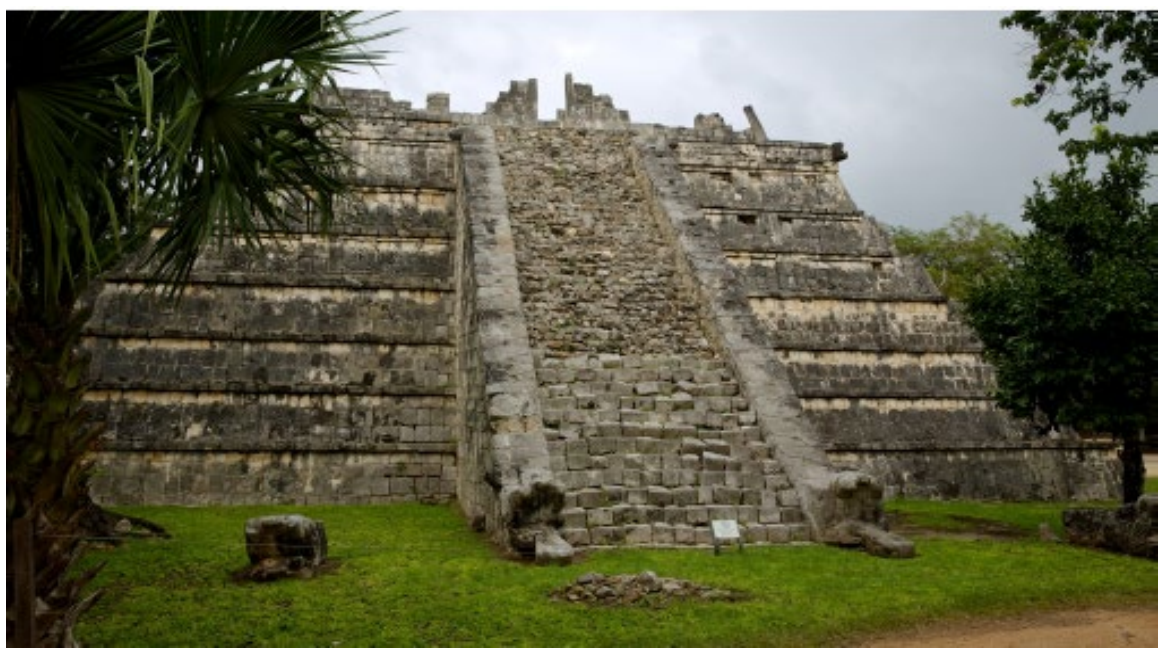

Figura 9. Estructura 3C1, llamada El Osario o la Tumba del Gran Sacerdote (Fotografía Orlando Casares). 


\section{ASTRONOMÍA, ELEMENTOS ACUÁTICOS Y URBANISMO.}

En términos astronómicos, en ambos asentamientos precolombinos ha sido difundido el uso de algunas de sus principales estructuras para la observación diurna y/o nocturna. Pero las similitudes van más allá de ese dato. Las principales estructuras que figuran en ambos sitios, están relacionadas con dos eventos solares como son los denominados equinoccios y los pasos del Sol por el cenit. Urbanísticamente hablando, las estructuras mencionadas se ubican en un grupo arquitectónico que directamente las conecta con un cenote y la fachada principal de la estructura tiene la misma dirección hacia la calzada que conecta la fuente de agua con el grupo mencionado.

Otro de los aspectos que comparten similitudes, son las ofrendas encontradas en su interior, que en el Templo de las Siete Muñecas consta como su nombre lo indica, de siete figuras burdamente elaboradas de barro y depositadas en el altar central, mismo que se ha propuesto como parte de un observatorio cenital pero que las excavaciones de su época no permitieron su reconstrucción y no respetaron algunos elementos in situ. Cabe señalar, que en El Castillo de Chichén Itzá las ofrendas interiores se ubican en su subestructura pero que para el caso de El Osario, la correspondencia es mayor, debido a que en su interior se ubica una caverna artificial que pudo ser usada como observatorio cenital, tal como lo señala Ruben Morante (2014) y tiene una ofrenda con siete humanos, número que igual que la ofrenda depositada en la Subestructura 1 de Dzibilchaltún.

Con relación a los eventos astronómicos que hoy conocemos como equinoccios, los arqueólogos Ivan Sprajc y Pedro Sánchez ha propuesto la inexistencia de los mismos o su falta de relación el evento en su sentido puramente astronómico, indicando que no siempre puede apreciarse en la fecha astronómica e incluso que en otras fechas (cercanas) se aprecia mejor (Sprajc 2015: 67 - 70). Esta hipótesis parece contradecir aquellos trabajos que anteponen al equinoccio como uno de los principales eventos astronómicos registrados por los mayas, pero las estadísticas de muchos estudios recientes han revelado que en su mayoría, las estructuras con alineamientos astronómicos corresponden a eventos solsticiales, a fechas de importancia calendárica y con relación a las salidas y puestas de Venus como la Luna (Sprajc 2012: 954 - 956).

El cálculo astronómico del equinoccio difícilmente existió en la manera que actualmente es realizado, pero eso no implica que desconocieran el principio a partir de un cálculo entre las distancias de dos eventos solares extremos como los solsticios, en los que se indican los cambios más importantes en el clima por 
venir (primavera y otoño) por lo que éste conocimiento -y como ya se ha recalcado en otras publicaciones anteriores- era necesario para una sociedad agrícola. Así que, siendo cuartos de año o equinoccios, su denominación la tomaremos como equivalente y parte de una referencia astronómica al cambio de estación.

Sin entrar a fondo a un debate sobre la existencia o no de los equinoccios en su sentido astronómico, asumiremos su existencia como una fecha calculada a partir de dos criterios, como un punto intermedio entre las distancias existentes en días de un solsticio a otro y para el caso concreto de los dos sitios mencionados, para indicar la proximidad a las fechas del paso del Sol por el cenit del lugar según la latitud de cada uno (figura 10), considerándolas como parte de un culto religioso asociado a la entrada a la temporada de lluvias.

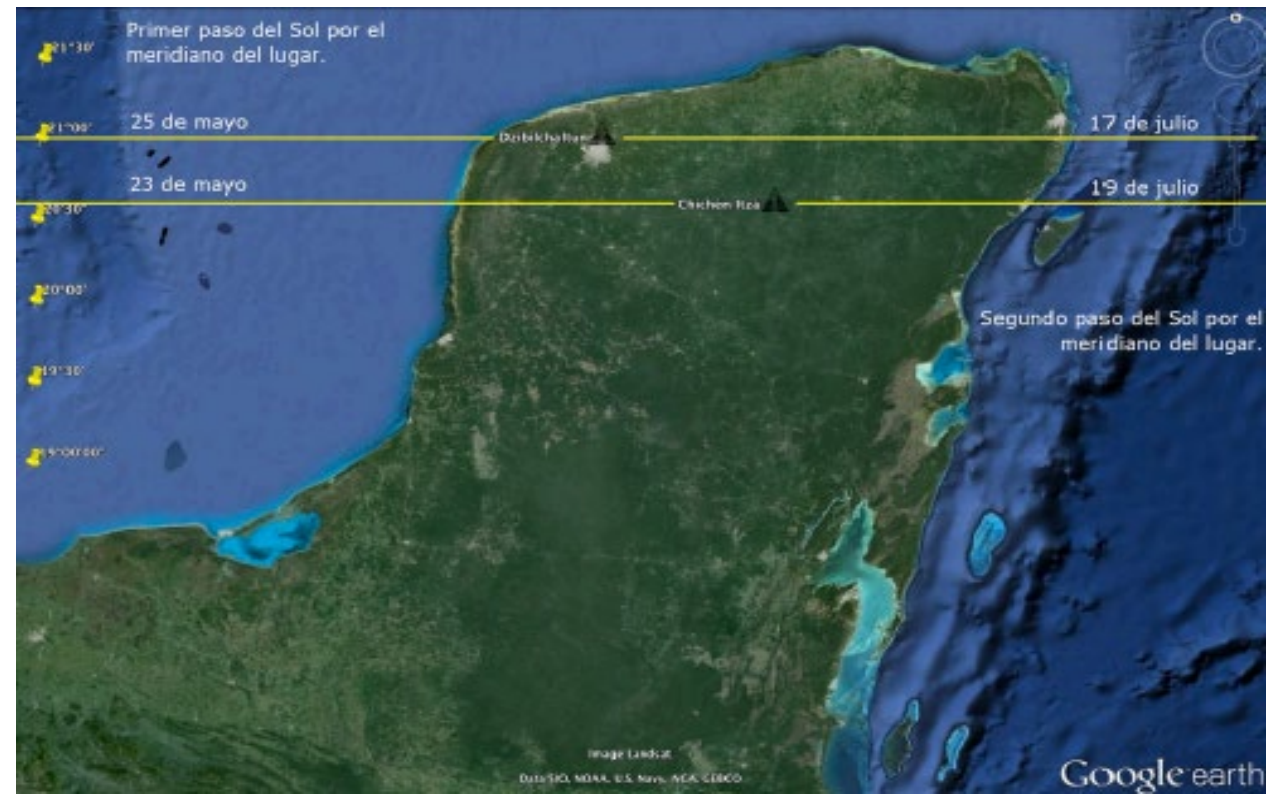

Figura 10. Mapa que señala la diferencia en fechas según las latitudes Dzibilchaltún y Chichén Itzá con las fechas del primer y segundo paso del Sol por el Cenit.

Dicha propuesta se respalda usando información etnográfica, en la que se ha registrado que diferentes grupos mayas de la península celebran sus festividades agrícolas y peticiones de lluvia en fechas cercanas al evento astronómico del paso del Sol por el cenit (Casares 2014), razón por la cual, no es descabellado pensar que sea éste y no los equinoccios quienes tuvieran mayor importancia en términos religiosos. 
De igual forma, la disposición arquitectónica del espacio en la que un sacbé conecta a las estructuras con una de las principales fuentes de agua, en éste caso de los cenotes encontrados en ambos sitios, siendo que en Chichén Itzá se repite el patrón dos veces con el conjunto de El Osario con su escalinata principal viendo al oriente y señalando hacia el cenote Xlacah y posteriormente al norte con la Gran Nivelación en la que la escalinata norte (la principal) de la estructura conocida como El Castillo apuntando hacia el Cenote Sagrado. Este rasgo vincula espacialmente a las estructuras con las fuentes de agua, que simbólicamente representan una entrada al inframundo.

\section{CONSIDERACIONES FINALES}

La peculiaridad de éste patrón urbanístico entre éstos dos sitios nos plantea nuevas interrogantes acerca de lo que conocemos previamente sobre el patrón de asentamiento en las ciudades mayas, ¿fue un arreglo arquitectónico propio de una temporalidad? ¿Era parte de algún culto religioso que involucraba elementos acuáticos o relacionados con a agricultura y/o la fertilidad?

Aunque sólo la comparativa entre éstas dos urbes no es suficiente, siendo Dzibilchaltún de una temporalidad más temprana a la de Chichén Itzá, ambas se traslapan a partir del 800 d.C. durante el clásito terminal, siendo que Chichén Itzá deja influencias en diferentes sitios arqueológicos, uno de ellos Dzibilchaltún, visible en la construcción de la Estructura 36 del Dzibilchaltún por sus estilos arquitectónicos (Góngora 2015).

Habrá que seguir haciendo análisis de las disposiciones arquitectónicas de diferentes sitios arqueológicos no sólo del norte del área maya sino de otras ciudades para ir delimitando variantes y poder responder de mejor forma a éstas y otras interrogantes que irán surgiendo, pero éste acercamiento, nos plantea una visión más compleja de las formas en las que el conocimiento astronómico de los mayas pudo haberse empleado dentro de los entramados religiosos que conformaron a su sociedad. 


\section{AGRADECIMIENTOS:}

Al Dr. Jesús Galindo Trejo, por sus comentarios, correcciones y constante apoyo en temas de arqueoastronomía. De igual forma al Dr. Stanislaw Iwaniszewski por la invitación a participar en ésta destacada revista de investigación. Por último, al arqueólogo y epigrafista Guillermo Kantún Rivera, quien a través de sus observaciones en torno a los elementos arquitectónicos, fue posible plantearse esta comparativa que seguramente creará un nuevo punto de partida para pensar el urbanismo y la astronomía a través de los cultos a la agricultura y otros personajes religiosos mayas.

\section{BIBLIOGRAFÍA.}

- Andrews IV, Wyllys; Andrews V, Wyllys (1980) Excavations at Dzibilchaltun, Yucatán, México. Middle American Research Institute. Tulane University, New Orleans.

- Andrews V, Wyllys (1978) Dzibilchaltún. Instituto Nacional de Antropología e Historia. México.

- Andrews, George (1987) Maya Cities. Placemaking and Urbanization. Norman, University of Oklahoma Press. Arochi Flores, Luis E. (1998) La Pirámide de Kukulkán: Su simbolismo solar. Editorial Panorama. México.

- Casares Contreras, Orlando (2001) "Una revisión arqueoastronómica en la estructura 1-Sub de Dzibilchaltún, Yucatán. Temas Antropológicos. Universidad Autónoma de Yucatán. 23: 5-15.

- Casares Contreras, Orlando(2014) Bix u náatik maya wíinik le ka'ano. Un estudio antropológico sobre la visión del cielo de los mayas. PUBLICIA. Saarbrüken, Alemania.

- Cobos Palma, Rafael (1997) Katún y Ahau: Fechando el fin de Chichén Itzá. Identidades sociales en Yucatán, C. Lara (comp.) pp ¿?. Universidad Autónoma de Yucatán. México.

- Cobos Palma, Rafael (1998) Chichen Itza y el Clásico Terminal en las Tierras Bajas Mayas. XI Simposio de Investigaciones Arqueológicas en Guatemala. J. Laporte y H. Escobedo (editores), pp. 915 - 930. Museo Nacional de Arqueología y Etnología, Guatemala. 
- Coggins Clemency, Drucker, David (1988) The observatory at Dzibilchaltún. New Directions in American Archaeoastronomy (Aveni ed.). BAR International Series. 454: 17-56.

- Fernández Souza, Lilia (1999) Un contexto funerario en la Plaza del Osario de Chichén Itzá. Temas Antropológicos. UADY. Vol 2: 264-279.

- Gallareta Negrón, Tomás; A. P. Andrews y otros. (1989) Isla Cerritos: Un puerto maya prehispánico de la costa norte de Yucatán, México. II Coloquio Internacional de Mayistas, (Tomo II) pp. 311-332. UNAM, México.

- Galindo Trejo, Jesús (1994) Arqueoastronomía en América Antigua. CONACYT - Sirius. España.

- Góngora Salas, Ángel (2015) El Reino de Joo ¿Era la antigua Ichkaantijo Dzibilchaltún?. Uniprent. Mérida, México.

- Kubler, George (1961) Chichén Itzá y Tula. Estudios de Cultura Maya. UNAM. Vol. 1: $47-80$.

- Montero García, Arturo (2013) El Sello del sol en Chichén Itzá. Fundación Cultural Armella Spitalier. México, D.F.

- Montero G., Arturo; Galindo T.,Jesús; Wood C.,David (2014) El Castillo de Chichén Itzá. Un monumento al tiempo. Arqueología Mexicana. Vol. 21, 127: 80-83.

- Morante López, Rubén (2014) El Osario de Chichén Itzá: ¿tumba del gran sacerdote u observatorio subterráneo?. La interpretación en la Astronomía Cultural. Memorias de la Segunda Jornada de Astronomía Cultural y la Tercera Escuela Interamericana de Astronomía Cultural, pp. 28 - 31. México, DF.

- Schmidt, Peter (1994) Chichén Itzá.1 Mexicana. II ,10: 20 - 25.

- Schmidt, Peter (2011) Los oficiantes de la pirámide del Osario en Chichén Itzá, Yucatán. XXIV Simposio de Investigaciones Arqueológicas en Guatemala, pp. 1163 - 1179. B. Arroyo y otros (editores). Museo Nacional de Arqueología y Etnología, Guatemala. 
- Sprajc, Ivan; Sánchez Nava, Pedro (2012) "Orientaciones astronómicas en la arquitectura Maya de las Tierras Bajas: Nuevos datos e interpretaciones". En XXV Simposio de Investigaciones Arqueológicas en Guatemala", pp. 952972. B. Arroyo y otros (editores). Ministerio de Cultura y Deportes, Instituto de Antropología e Historia y Asociación Tikal.

- Sprajc, Ivan; Sánchez Nava, Pedro(2015) Orientaciones astronómicas en la arquitectura maya de las Tierras Bajas. Instituto Nacional de Antropología e Historia. Ciudad de México, México.

- Thompson, Eric S.; Thompson, Edward (1938) The High Priest's Grave, Chichen Itza, Yucatan, Mexico. Anthtropology Series Vol. XXVII. Field Museum of Natural History, Chicago. 